TITLE:

\title{
Nonlinear optimal oil damper design in seismically controlled multi-story building frame
}

$\operatorname{AUTHOR}(S):$

Adachi, F.; Yoshitomi, S.; Tsuji, M.; Takewaki, I.

\section{CITATION:}

Adachi, F....[et al]. Nonlinear optimal oil damper design in seismically controlled multistory building frame. Soil Dynamics and Earthquake Engineering 2013, 44: 1-13

\section{ISSUE DATE:}

2013-01

URL:

http://hdl.handle.net/2433/159444

\section{RIGHT:}

@ 2012 Elsevier Ltd.; この論文は出版社版でありません。引用の際には 出版社版をご確認ご利用ください。; This is not the published version. Please cite only the published version. 


\title{
Nonlinear Optimal Oil Damper Design in Seismically Controlled Multi-Story Building Frame
}

\author{
F. Adachi, S. Yoshitomi ${ }^{+}$, M. Tsuji and I. Takewaki ${ }^{*}$ \\ Department of Architecture and Architectural Engineering, Kyoto University \\ Kyotodaigaku-Katsura, Nishikyo-ku, Kyoto 615-8540, Japan
}

\begin{abstract}
The purpose of this paper is to propose a practical method for optimum design of non-linear oil dampers with relief mechanism installed in multi-story framed building structures. The optimum design problem is formulated so as to minimize the maximum interstory drift or maximum acceleration of top story under design earthquakes in terms of a set of relief forces subject to an inequality constraint on the maximum ratio of the damping force to the relief force and an equality constraint on the sum of relief forces of oil dampers. The proposed method to solve the optimum design problem is a successive procedure which consists of two steps. The first step is a sensitivity analysis by using nonlinear time-history response analyses, and the second step is a modification of the set of relief forces based upon the sensitivity analysis. An advanced reduction method based on static condensation of the frame and energy equivalence transformation of oil dampers is proposed and introduced into the optimum procedure to reduce the computational load. Numerical examples are conducted to demonstrate the effectiveness and validity of the proposed design method.
\end{abstract}

Key words: Oil damper, Relief force, Non-linear response, Optimal design, Sensitivity analysis, Seismic controlled structure, Multi-story building, Displacement and acceleration design

\footnotetext{
*Corresponding author: E-mail takewaki@archi.kyoto-u.ac.jp

+Present address: Ritsumeikan University, Kusatsu 525-8577, Japan
} 


\section{Introduction}

There are a variety of passive dampers for building structures under earthquake ground motions [1-4]. Hysteretic steel dampers (shear deformation type, buckling restrained type), viscous wall-type dampers, viscous oil dampers, visco-elastic dampers, friction dampers are representative ones. Recently viscous oil dampers (called oil dampers hereafter) are often used from the viewpoints of stable mechanical properties, low frequency and temperature dependencies and cost effectiveness, etc. together with hysteretic steel dampers. It should be emphasized that, during the 2011 Tohoku (Japan) earthquake, the Osaka WTC building of 256(m) high was shaken so hard irrespective of its long distance (800km) from the epicenter [5]. It is said that this results from the resonance with the so-called long-period ground motion. To respond to this unfavorable situation, the retrofit of this building is under planning with oil dampers and hysteretic steel dampers. Since oil dampers induce large internal forces into building frames under intensive ground motions, it is usual to introduce the so-called relief mechanism in those oil dampers. When the internal force in the oil damper arrives at the relief force, the damping coefficient becomes small compared to the initial one and the maximum force in the oil damper is kept in a reasonable range.

Many research works have been accumulated so far on the damper optimization [6-17]. While most of them deal with linear responses, quite a few treat non-linear responses in building structures or dampers [12, 18, 19]. However, there is no research on the optimization of location and quantity of dampers which deals directly with non-linear responses and includes simple and systematic algorithms.

The purpose of this paper is to propose a practical procedure aimed at finding the optimal distribution of relief forces of oil dampers so as to minimize the maximum interstory drift or the maximum top-story acceleration of a planar frame subjected to a set of design earthquake ground motions under the constraint on the sum of relief forces of oil dampers and on the limit state of oil dampers. The proposed procedure enables structural designers to derive a series of 
optimal distribution of relief forces of oil dampers with respect to the level of the sum of relief forces of oil dampers which is useful in seeking for the relation between the optimal response level and the quantity of oil dampers. Numerical examples reveal some features of the optimal distribution of relief forces of oil dampers for different design objectives (deformation or acceleration) and for different damper arrangements (whole distribution or lower concentrated allocation).

\section{Modeling of oil dampers with relief mechanism}

Consider oil dampers with a relief mechanism and a planar frame model with those oil dampers as shown in Fig.1(a). The damping force - velocity relation of an oil damper is shown in Fig.1(b). Although there are two oil dampers in each story, the properties are specified as the total amount in each story.

Let $c_{1 j}, c_{2 j}, d_{\mathrm{R} j}$ denote the initial damping coefficient of the oil damper below the relief force, the second damping coefficient of the oil damper above the relief force and the relief force in the jth story, respectively. The ratio of these initial and second damping coefficients is specified here as $\gamma_{j}=c_{2 j} / c_{1 j}=0.05$. The limit value of the damping force of oil dampers in the $j$ th story is denoted by $f_{\mathrm{CRj}}$ and the ratio $f_{\mathrm{CRj}} / d_{\mathrm{R} j}$ is given by $f_{\mathrm{CRj}} / d_{\mathrm{Rj}}=1.1$. As usual, $f_{\mathrm{CR} j}$ is treated to depend on $d_{\mathrm{R} j}$

Since the frame including oil dampers with the relief mechanism exhibits a non-linear behavior, time-history response analysis may be inevitable for accurate response evaluation. For this reason, time-history response analysis is used here for the evaluation of responses and their sensitivities to the variation of relief forces.

Let $\delta_{j \max }$ denote the maximum interstory drift in the $j$ th story. $D_{\max }$ represents the maximum value among $\left\{\delta_{j \max }\right\}$. On the other hand, $A_{\max }$ indicates the maximum absolute acceleration at the top floor. It is useful to define the ratio $r_{j \max }$ of the maximum response damping force $f_{j \max }$ in the oil dampers in the $j$ th story to the corresponding relief force $d_{\mathrm{R} j}$ 
as

$$
r_{j \max }=\frac{f_{j \max }}{d_{\mathrm{Rj}}}
$$

This quantity is called the maximum damping force ratio later.

It is usual in the ordinary earthquake resistant design of buildings to define a set of design earthquake ground motions. For this purpose, let us introduce 'envelopes' of $\delta_{j \max }, D_{\max }$, $A_{\max }, r_{j \max }$ for all the design earthquake ground motions and denote them as $\hat{\delta}_{j \max }, \hat{D}_{\max }$, $\hat{A}_{\max }, \hat{r}_{j \max }$.

\section{Formulation of problem of optimal oil damper placement}

Consider an $\mathrm{N}$-story planar building frame as shown in Fig.1. The design problem treated in this paper may be stated as follows.

[Problem] Find $\mathbf{d}_{\mathrm{R}}=\left\{d_{\mathrm{Rj}}\right\}$ so as to minimize $F$ subject to

$$
\begin{aligned}
& \sum_{j=1}^{N} d_{\mathrm{Rj}}=\bar{C}_{\mathrm{d}} \\
& r_{j \max } \leq \alpha \quad(j=1,2, \cdots, N)
\end{aligned}
$$

In this problem, $\bar{C}_{\mathrm{d}}$ is the specified sum of relief forces and $\alpha$ is the common specified value of $f_{\mathrm{CRj}} / d_{\mathrm{Rj}} \cdot \hat{D}_{\max }$ or $\hat{A}_{\max }$ is employed as $F$. For simplicity of expression, $\hat{D}_{\max }$ and $\hat{A}_{\max }$ are expressed simply as $D_{\max }$ and $A_{\max }$ later, respectively.

It may be time-consuming to use a full frame model especially in the time-history response analysis. To overcome this difficulty, a reduced model is introduced.

\section{Introduction of reduced model}

\subsection{Static condensation of frame model into reduced model}

In this section, only the reduction of a frame without oil damper is dealt with [20]. Let 
$\mathbf{M}, \mathbf{K}, \mathbf{u}$ and $\mathbf{r}$ denote the system mass matrix, the system stiffness matrix, the nodal displacement vector and the influence coefficient vector of the frame, respectively. The equations of motion of the undamped $N$-story planar building frame subjected to $\ddot{u}_{g}$ may be expressed as

$$
\mathbf{M u ̈}+\mathbf{K u}=-\mathbf{M r u ̈}{ }_{g}
$$

Let us describe Eq.(4) in more detail as follows.

$$
\left[\begin{array}{cc}
\mathbf{m} & \mathbf{0} \\
\mathbf{0} & \mathbf{J}
\end{array}\right]\left\{\begin{array}{c}
\ddot{\mathbf{y}} \\
\ddot{\boldsymbol{\theta}}
\end{array}\right\}+\left[\begin{array}{ll}
\mathbf{K}_{11} & \mathbf{K}_{12} \\
\mathbf{K}_{21} & \mathbf{K}_{22}
\end{array}\right]\left\{\begin{array}{l}
\mathbf{y} \\
\boldsymbol{\theta}
\end{array}\right\}=-\left[\begin{array}{cc}
\mathbf{m} & \mathbf{0} \\
\mathbf{0} & \mathbf{J}
\end{array}\right]\left\{\begin{array}{l}
\mathbf{1} \\
\mathbf{0}
\end{array}\right\} \ddot{u}_{g}
$$

In Eq.(5), $\mathbf{y}$ denotes the set of nodal horizontal displacements and $\boldsymbol{\theta}$ indicates the set of nodal vertical and rotational displacements. The matrices $\mathbf{m}$ and $\mathbf{J}$ are the lumped mass matrices with respect to $\mathbf{y}$ and $\boldsymbol{\theta}$, respectively. $\mathbf{K}_{11}, \mathbf{K}_{12}, \mathbf{K}_{21}, \mathbf{K}_{22}$ are the stiffness submatrices defined for $\mathbf{y}$ and $\boldsymbol{\theta}$. $\quad \mathbf{1}$ and $\mathbf{0}$ are the vector consisting of unity only and the null vector. Eq.(5) can be expressed alternatively as a set of equations.

$$
\begin{aligned}
& \mathbf{m} \ddot{\mathbf{y}}+\mathbf{K}_{11} \mathbf{y}+\mathbf{K}_{12} \boldsymbol{\theta}=-\mathbf{m} \mathbf{1} \ddot{u}_{g} \\
& \mathbf{J} \ddot{\boldsymbol{\theta}}+\mathbf{K}_{21} \mathbf{y}+\mathbf{K}_{22} \boldsymbol{\theta}=\mathbf{0}
\end{aligned}
$$

The neglect of the inertia term $\mathbf{J} \ddot{\boldsymbol{\theta}}$ in Eq.(6b) leads to

$$
\boldsymbol{\theta}=-\mathbf{K}_{22}{ }^{-1} \mathbf{K}_{21} \mathbf{y}
$$

Substitution of Eq.(7) into Eq.(6a) provides

$$
\mathbf{m} \ddot{\mathbf{y}}+\left(\mathbf{K}_{11}-\mathbf{K}_{12} \mathbf{K}_{22}{ }^{-1} \mathbf{K}_{21}\right) \mathbf{y}=-\mathbf{m} \mathbf{1} \ddot{u ̈}_{g}
$$

The mass and stiffness matrices of the reduced model may be expressed by

$$
\overline{\mathbf{M}}=\mathbf{m}, \quad \overline{\mathbf{K}}=\mathbf{K}_{11}-\mathbf{K}_{12} \mathbf{K}_{22}{ }^{-1} \mathbf{K}_{21}
$$

Fig.2 shows a planar frame model and its reduced model. 


\subsection{Model reduction of oil dampers with relief mechanism}

The reduction of oil dampers is explained in this section [21].

Let $\omega^{(1)}$ and $\bar{\omega}^{(1)}$ denote the fundamental natural circular frequency of the original frame model without oil damper and that of the reduced model, respectively. In evaluating $\omega^{(1)}$, the vertical nodal mass of the same value of the horizontal one is taken into account and the rotational inertia is neglected. $\bar{\omega}^{(1)}$ can be evaluated from $\overline{\mathbf{M}}$ and $\overline{\mathbf{K}}$ in Eq.(9). The modes $\mathbf{u}^{(1)}$ and $\overline{\mathbf{u}}^{(1)}$ indicate the lowest eigenmode of the original model and that of the reduced model. Let $\Delta w_{j}^{(1)}$ and $\Delta \bar{u}_{j}^{(1)}$ represent the damper elongation component in the lowest eigenmode of the original model and the interstory drift component in the lowest eigenmode of the reduced model. Assume that $\Delta w_{j}^{(1)}$ and $\Delta \bar{u}_{j}^{(1)}$ are normalized appropriately. The coefficients $c_{j}$ and $\bar{c}_{j}$ denote the damper damping coefficient of the original model and that of the reduced model. Let $\beta$ and $\bar{\beta}$ denote the vibration-amplitude coefficients depending on the normalization of $\Delta w_{j}^{(1)}$ and $\Delta \bar{u}_{j}^{(1)}$.

The dissipated energies of both models in the lowest vibration mode can be expressed by

$$
S_{j}=\beta^{2} \pi c_{j} \omega^{(1)} \Delta w_{j}^{(1) 2}, \quad \bar{S}_{j}=\bar{\beta}^{2} \pi \bar{c}_{j} \bar{\omega}^{(1)} \Delta \bar{u}_{j}^{(1) 2}
$$

The equivalence of dissipated energies between both models may be expressed by

$$
S_{j}=\bar{S}_{j}
$$

Substitution of Eqs.(10a, b) into Eq.(11) leads to the expression of $\bar{c}_{j}$ in terms of $c_{j}$.

$$
\bar{c}_{j}=\left(\frac{\beta}{\bar{\beta}}\right)^{2} \frac{\omega^{(1)} \Delta w_{j}^{(1) 2}}{\bar{\omega}^{(1)} \Delta \bar{u}_{j}^{(1) 2}} c_{j}=\left(\frac{\beta}{\bar{\beta}}\right)^{2} \tilde{c}_{j}
$$

In Eq.(12) the expression except $(\beta / \bar{\beta})^{2}$ is indicated by $\tilde{c}_{j}$. In order to determine these 
coefficients $\beta$ and $\bar{\beta}$ of vibration amplitudes, let us introduce the equivalent condition of additional damping ratios of both models. The additional damping ratios of both models under the approximation of neglect of non-diagonal terms may be expressed by

$$
\begin{aligned}
h_{\mathrm{d}}^{(1)} & =\frac{\mathbf{u}^{(1) T} \mathbf{C}_{\mathrm{d}} \mathbf{u}^{(1)}}{2 \omega^{(1)} \mathbf{u}^{(1) T} \mathbf{M} \mathbf{u}^{(1)}} \\
\bar{h}_{\mathrm{d}}^{(1)} & =\frac{\overline{\mathbf{u}}^{(1) T} \overline{\mathbf{C}}_{\mathrm{d}} \overline{\mathbf{u}}^{(1)}}{2 \bar{\omega}^{(1)} \overline{\mathbf{u}}^{(1) T} \overline{\mathbf{M}} \overline{\mathbf{u}}^{(1)}}=\left(\frac{\beta}{\bar{\beta}}\right)^{2} \frac{\overline{\mathbf{u}}^{(1) T} \tilde{\mathbf{C}}_{\mathrm{d}} \overline{\mathbf{u}}^{(1)}}{2 \bar{\omega}^{(1)} \overline{\mathbf{u}}^{(1) T} \overline{\mathbf{M}} \overline{\mathbf{u}}^{(1)}}=\left(\frac{\beta}{\bar{\beta}}\right)^{2} \tilde{h}_{\mathrm{d}}^{(1)}
\end{aligned}
$$

In Eq.(13b), $\tilde{h}_{\mathrm{d}}^{(1)}$ indicates the expression except $(\beta / \bar{\beta})^{2}$. By equating Eqs.(13a, b), the following relation can be drawn.

$$
\left(\frac{\beta}{\bar{\beta}}\right)^{2}=\frac{h_{\mathrm{d}}^{(1)}}{\tilde{h}_{\mathrm{d}}^{(1)}}
$$

Substitution of Eq.(14) into Eq.(12) provides the expression of $\bar{c}_{j}$ in terms of $\tilde{c}_{j}$ (also in terms of $c_{j}$ )

$$
\bar{c}_{j}=\frac{h_{\mathrm{d}}^{(1)}}{\tilde{h}_{\mathrm{d}}^{(1)}} \tilde{c}_{j}
$$

The determination procedure of relief forces $\bar{d}_{\mathrm{Rj}}$ in the reduced model will be shown next. Let us assume that both models vibrate in the lowest mode and the maximum damping forces of both models just reach to the relief forces. In this case, the dissipated energies are also expressed in terms of relief forces.

$$
S_{j}=\beta \pi d_{\mathrm{R} j} \Delta w_{j}^{(1)}, \quad \bar{S}_{j}=\bar{\beta} \pi \bar{d}_{\mathrm{Rj}} \Delta \bar{u}_{j}^{(1)}
$$

From Eqs.(11) and (16), $\bar{d}_{\mathrm{Rj}}$ can be expressed in terms of $d_{\mathrm{Rj}}$. 


$$
\bar{d}_{\mathrm{R} j}=\left(\frac{\beta}{\bar{\beta}}\right) \frac{\Delta w_{j}^{(1)}}{\Delta \bar{u}_{j}^{(1)}} d_{\mathrm{R} j}
$$

The relief force of the reduced model may then be expressed in terms of that of the original model as

$$
\bar{d}_{\mathrm{R} j}=\sqrt{\frac{h_{\mathrm{d}}^{(1)}}{\tilde{h}_{\mathrm{d}}^{(1)}}} \frac{\Delta w_{j}^{(1)}}{\Delta \bar{u}_{j}^{(1)}} d_{\mathrm{R} j}
$$

The reduction of oil dampers is based on the assumption of proportional damping expressed by Eq.(13). Its accuracy and validity will be made clear in Section 4.3 where the comparison of the maximum interstory drifts and the maximum top-floor acceleration is provided between the frame model and the proposed reduced model.

It should also be reminded that the model reduction in Section 4.1 has been made by ignoring the vertical components of oil damper forces. However, the important aspect is whether these components are influential for the structural responses. This influence will be investigated in the following section.

\subsection{Accuracy of reduced model}

The accuracy of the reduced model proposed in Sections 4.1 and 4.2 is discussed here. Consider a 10-story 3-bay steel building frame. The story height is $4(\mathrm{~m})$ and the span length is $7(\mathrm{~m})$. The floor mass is $120 \times 10^{3}(\mathrm{~kg})$. The member cross-sections are specified based on an existing building. The fundamental natural period of the frame without dampers is 1.39(s) and the structural damping ratio of the frame is 0.02 (stiffness-proportional damping). Although the stiffness-proportional damping is adopted here, non-proportional damping can also be used without difficulty. The member second moments of area and cross-sectional areas are shown in Table 1. The input ground motion is El Centro NS 1940 (unscaled). The time-history response analysis is conducted by the Newmark-beta method and the time increment is 0.002 (s). 
Two oil dampers are installed in every story with the support of V-type braces as shown in Fig.1(a). The initial damping coefficient (below relief force) of oil dampers is set to $5.3 \times 10^{6}(\mathrm{~N} \times \mathrm{s} / \mathrm{m})$ in every story so as to attain the additional damping ratio of 0.1 based on the assumption of neglect of non-diagonal terms in orthogonalization of damping matrices. The ratio of the second damping coefficient (above relief force) to the initial one is specified as 0.05 both in the original frame model and the reduced model. It can been confirmed numerically [22] that, if the ratio $k$ of the supporting member stiffness to the corresponding story stiffness is larger than about 1.0, the effect of the supporting member stiffness can be neglected in the response of interstory drifts. Fig. 3 shows the effect of this ratio on the response of interstory drifts.

The relief forces of oil dampers are specified here so that those relief forces are 0.5 or 1.0 of the response damping forces of oil dampers without relief mechanism (linear oil dampers). Obviously, when this ratio $L$ is 1.0 , the oil dampers behave linearly, i.e. do not go beyond the relief force.

Fig. 4 shows the damping coefficient distributions of oil dampers in the frame model and the reduced model and Fig.5 presents the relief force distributions of oil dampers in the frame model and the reduced model for two ratios $L=1.0,0.5$. The reduction of damping coefficients in upper stories in the reduced model may result from the effect of overall flexural behavior of the frame due to elongation of columns.

Fig.6 illustrates the maximum interstory-drift distributions in the frame model and the reduced model for two ratios $L=1.0,0.5$. Both models exhibit a good correspondence. Fig.7 shows the maximum acceleration distributions in the frame model and the reduced model for two ratios $L=1.0$, 0.5 and Fig.8 presents the distributions of maximum damping force ratios (maximum response damping force/ relief force) in the frame model and the reduced model for two ratios $L=1.0,0.5$. It can be drawn from Figs.6-8 that the proposed reduced model can simulate the response of the frame model within a reasonable accuracy. 


\section{Proposed practical procedure for optimal oil damper design}

A practical procedure for optimal oil damper design is proposed in this paper for optimizing the oil damper allocation and reducing the computational load. There are three practical aspects: (1) use of the reduced model for computational efficiency in non-linear time-history response analysis, (2) approximate algorithm to remove oil dampers in case of the violation of constraints on damping force (avoidance of cumbersome algorithm for finding a path to a feasible design space satisfying the constraints), (3) search of a series of optimal oil damper distributions for different damper quantities (different levels of cost). Eigenvalue analysis for an original frame model is conducted once which requires an extremely short computational time compared to that for the repeated non-linear time-history response analysis.

Fig.9 illustrates the approximate solution procedure using the proposed reduced model. The design algorithm may be summarized as follows:

[Step 1] Conduct a linear time-history response analysis of the original frame model with linear oil dampers for design earthquake ground motions. Find the critical earthquake ground motion giving the response envelope. Adopt response envelope damper forces for the linear damper model (original frame model) as the initial relief forces of oil dampers. This set of relief forces certainly satisfies the constraint on damping forces. The sum of relief forces of oil dampers is determined here and reduced sequentially in the subsequent step.

[Step 2] Produce $N$ candidate designs of relief forces in which a small relief force $\Delta d_{\mathrm{R}}$ is reduced from the present relief force in each story and transform these $N$ models into the corresponding reduced models.

[Step 3] Compute the maximum damping force ratio $r_{j \max }=f_{j \max } / d_{\mathrm{Rj}}$ and the objective function for each reduced model constructed in Step 2 through nonlinear time-history response analysis. If the constraint on the maximum damping force ratio is violated in 
one story, remove the oil damper in that story. Repeat this procedure until the constraints on the maximum damping force ratio are satisfied in all stories.

[Step 4] Select the best candidate attaining the minimum objective function from the candidate designs produced in Steps 2 and 3.

[Step 5] When an oil damper is removed from the reduced model in Step 3, the corresponding oil damper in the frame model is removed. Then go to Step 2.

The computational time required for the reduced model is approximately $20-25 \%$ of that for the frame model in the numerical examples presented in the following section. The main part of the computational time is governed by the time-history response analysis for candidate designs of the number smaller than or equal to the number of stories. In the time-history response analysis, the reduced model has remarkable efficiency against the frame model.

\section{Numerical examples}

The frame shown in Section 4.3 is used here again. El Centro NS 1940 (unscaled), Taft EW 1952 (unscaled) and Hachinohe NS 1968 (unscaled) are employed as the design earthquake ground motions. Since oil dampers do not influence the natural periods of a building frame so much, the introduction of multiple design earthquake ground motions appears to lead to self-evident result by using the most critical excitation. The investigation on response envelopes is shown in Appendix 1 and it was made clear that El Centro NS 1940 is the critical input in this case. For this reason only a single ground motion (El Centro NS 1940) is used in this example.

While there is a constraint on $r_{j \max }$, Eq.(3), there is no limit on interstory drift.

\subsection{Damper allocation to all stories}

In the first example, oil dampers are allowed to be allocated to all stories.

Fig.10 shows the relation of $D_{\max }, A_{\max }$ with $C_{\mathrm{d}}$ in displacement design (Design D) in 
case of damper allocation to all stories (final response is evaluated by the frame model). On the other hand, Fig.11 presents the relation of $D_{\max }, A_{\max }$ with $C_{\mathrm{d}}$ in acceleration design (Design A) in case of damper allocation to all stories. The final response is evaluated by the frame model. It can be observed from Figs.10 and 11 that the relation of $D_{\max }, A_{\max }$ with $C_{\mathrm{d}}$ by the reduced model exhibits a relation similar to that by the frame model both in Design D and Design A. It can also be observed from Figs.10(a) and 11(a) that, in both Design D and Design A, the sum of relief forces of oil dampers can be decreased to almost the half of the initial value without the increase of the maximum interstory drifts. Furthermore, from Figs.10(b) and 11(b), Design A appears robust in the sense that the increase of the top-floor maximum acceleration is insensitive to the decrease of the sum of relief forces of oil dampers.

Fig.12 illustrates the relief force distributions in displacement design for several levels of the sum of relief forces of oil dampers (referred to as 'relief force level' later) in case of damper allocation to all stories. On the other hand, Fig.13 shows the relief force distributions in acceleration design for several relief force levels in case of damper allocation to all stories. In Design D, oil dampers in upper stories are removed in the early stage and larger relief forces are allocated to the stories attaining large interstory drifts. In Design A, oil dampers in middle stories are removed in the early stage and oil dampers with a certain amount are allocated to upper stories. Furthermore, larger relief forces are allocated to the stories attaining large interstory drifts as in Design D.

Fig.14 presents the maximum interstory-drift distributions in displacement design for several relief force levels in case of damper allocation to all stories (final response is evaluated by the frame model). Fig.15 illustrates the maximum interstory-drift distributions in acceleration design for several relief force levels in case of damper allocation to all stories (final response is evaluated by the frame model). It can be observed from Figs.14 and 15 that the maximum interstory-drift distributions in Design D are similar to those in Design A.

Fig.16 shows the maximum acceleration distributions in displacement design for several 
relief force levels in case of damper allocation to all stories (final response is evaluated by the frame model). Fig.17 presents the maximum acceleration distributions in acceleration design for several relief force levels in case of damper allocation to all stories (final response is evaluated by the frame model). While Design D and Design A exhibit a similar distribution of the maximum interstory drifts, they show a different distribution of the maximum acceleration. This may result from the fact that, while oil dampers (or an oil damper) in upper stories are removed in Design D at the later oil damper level, those oil dampers are retained in Design A even at the later oil damper level.

\subsection{Damper allocation to lower stories}

In the second example, oil dampers are allowed to be allocated to lower half stories.

Fig.18 illustrates the relation of $D_{\max }, A_{\max }$ with $C_{\mathrm{d}}$ in displacement design in case of damper allocation to lower stories (final response is evaluated by frame model). On the other hand, Fig.19 shows the relation of $D_{\max }, A_{\max }$ with $C_{\mathrm{d}}$ in acceleration design in case of damper allocation to lower stories (final response is evaluated by the frame model). It can be observed that Design D and Design A provide almost the same relation between the sum of relief forces of oil dampers and the maximum interstory drift (also almost the same relation between the sum of relief forces of oil dampers and the maximum top-floor acceleration). However more continuous relations of $D_{\max }, A_{\max }$ with $C_{\mathrm{d}}$ can be obtained in Design A compared to Design D. Once more continuous relations are obtained, structural designers can get the value of $C_{\mathrm{d}}$ sequentially for a continuous value of $D_{\max }, A_{\max }$.

Fig.20 presents the relief force distributions in displacement design for several relief force levels in case of damper allocation to lower stories. On the other hand, Fig.21 illustrates the relief force distributions in acceleration design for several relief force levels in case of damper allocation to lower stories. It can be observed that, while the optimization using the reduced model provides a relief force distribution similar to that using the frame model until a certain 
level $(3553 \mathrm{kN})$ of $C_{\mathrm{d}}$ in Design $\mathrm{D}$, it exhibits a different distribution even in an early level $(3553 \mathrm{kN})$ of $C_{\mathrm{d}}$ in Design A. It may result from the assumption stated at the end of Section 4.2 .

The maximum interstory-drift distributions in displacement design have been computed for several relief force levels in case of damper allocation to lower stories. On the other hand, the maximum interstory-drift distributions in acceleration design have been obtained for several relief force levels in case of damper allocation to lower stories. It can be said that a similar maximum interstory-drift distribution is observed both in the frame model and the reduced model.

The maximum acceleration distributions in displacement design have been evaluated for several relief force levels in case of damper allocation to lower stories. On the other hand, the maximum acceleration distributions in acceleration design have been computed for several relief force levels in case of damper allocation to lower stories. It can be said that a similar maximum acceleration distribution is observed both in the frame model and the reduced model.

Furthermore it has also be observed that both Design D and Design A provide similar distributions of the maximum interstory-drift distribution and the maximum acceleration distribution in this design example, i.e. the case allowed to be allocated to lower stories. It can be understood from Figs.17 (damper allocation to all the stories) and the corresponding result (damper allocation to lower stories) that the oil dampers in upper stories play an important role for the reduction of top-story acceleration (from 3.5-4.0 m/ $\mathrm{s}^{2}$ to $2.8-3.5 \mathrm{~m} / \mathrm{s}^{2}$ ).

\subsection{Comparison of optimal design with damper allocation to all stories and optimal design} with damper allocation to lower stories

It seems useful to compare the optimal design with damper allocation to all stories and the optimal design with damper allocation to lower stories. Fig.22 illustrates the relation of $D_{\max }, A_{\max }$ with $C_{\mathrm{d}}$ in displacement design (Design D). On the other hand, Fig.23 presents 
the relation of $D_{\max }, A_{\max }$ with $C_{\mathrm{d}}$ in acceleration design (Design A). It can be observed that the optimal design with damper allocation to all stories exhibits a performance superior to the optimal design with damper allocation to lower stories both in the maximum interstory drift and the maximum top-floor acceleration. This phenomenon can also be seen both in Design D and Design A.

\subsection{Global optimality of solution}

To demonstrate the global optimality of the solution derived by the proposed algorithm, numerical simulation has been conducted. One hundred designs have been generated with two given total relief forces ( $C_{\mathrm{d}}=1300 \mathrm{kN}, 3000 \mathrm{kN}$ ) provided by Eq.(2) and satisfying the constraint of Eq.(3). Fig.24 shows the maximum interstory drift and the maximum top-floor acceleration for such one hundred designs together with the response of the optimal design (Design D). The reduced model has been used for simulation. It should be noted that, since the objective function of Design D is $D_{\max }$ (not $A_{\max }$ ), $A_{\max }$ of some random designs is smaller than that for the optimal design. On the other hand, Fig.25 illustrates those ones for Design A. It can be observed that the global optimality of the solution derived by the proposed algorithm is guaranteed within a reasonable accuracy.

\section{Conclusions}

The following conclusions have been obtained.

(1) A practical procedure has been proposed which is aimed at finding the optimal distribution of relief forces of oil dampers so as to minimize the maximum interstory drift (Design D) or the maximum top-story acceleration (Design A) of a planar frame subjected to a set of design earthquake ground motions under the constraint on the sum of relief forces of oil dampers and on the limit state of oil dampers.

(2) The proposed procedure enables the derivation of a series of optimal distribution of relief 
forces of oil dampers with respect to the level of sum of relief forces of oil dampers which is useful for structural designers seeking for the relation between the optimal response level and the quantity of passive dampers.

(3) A feasible initial optimal distribution of relief forces of oil dampers can be found in the proposed procedure by adopting the response damper forces for a linear damper model as the relief forces of oil dampers.

(4) The characteristics of the optimal distribution of relief forces of oil dampers can be summarizes as follows:

* In Design D, oil dampers in upper stories are removed in the early stage and larger relief forces are allocated to the stories attaining large interstory drifts.

* In Design A, oil dampers in middle stories are removed in the early stage and oil dampers with a certain amount are allocated to upper stories. Furthermore, larger relief forces are allocated to the stories attaining large interstory drifts as in Design D.

* While Design D and Design A exhibit a similar distribution of the maximum interstory drifts, they show a different distribution of the maximum acceleration in the case of damper allocation to all stories. This may result from the difference of stories without dampers.

* In both Design D and Design A, the sum of relief forces of oil dampers can be decreased to almost the half of the initial value without the increase of the maximum interstory drifts.

* Design A is robust in the sense that the increase of the top-floor maximum acceleration is insensitive to the decrease of the sum of relief forces of oil dampers.

* As the sum of relief forces of oil dampers becomes small to some extent, the optimal distribution of relief forces is difficult to get continuously. This may result from the fact that the constraints on damping forces are easy to be violated.

The observations are based just on the results of the two applicative examples and further investigation is necessary for general conclusions.

(5) Design D and Design A provide almost the same relation between the sum of relief forces of 
oil dampers and the maximum interstory drift (also almost the same relation between the sum of relief forces of oil dampers and the maximum top-floor acceleration) in the case of damper allocation to lower stories. However a more continuous relation can be obtained in Design A.

\section{Acknowledgements}

Part of the present work is supported by the Grant-in-Aid for Scientific Research of Japan Society for the Promotion of Science (No.21360267, 24246095). The support is greatly appreciated.

Appendix A: Response envelope for multiple design earthquake ground motions

To investigate the response envelope for three design earthquake ground motions (El Centro NS 1940, Taft EW 1952 and Hachinohe NS 1968), the displacement and acceleration response spectra of $12 \%$ damping (the sum of $2 \%$ structural damping ratio and $10 \%$ damper damping ratio) were computed (see Fig.26). Since El Centro NS 1940 is regarded as the critical input, the response of the frame with linear oil dampers was computed first for El Centro NS 1940. The maximum damping forces of oil dampers under El Centro NS 1940 were selected as the initial relief forces. Then Taft EW 1952 and Hachinohe NS 1968 were input to the frame with the same oil dampers.

Table 2 shows the maximum interstory drifts and the maximum top-story accelerations for these three ground motions in two damper allocations. In addition, Fig.27 presents the maximum damping force ratios (to the relief force) for these three ground motions in two damper allocations. It can be observed that El Centro NS 1940 provides the response envelope. Since the response analysis is conducted for $L=1.0$ under El Centro NS 1940, the maximum damping force ratios are 1.0 for El Centro NS 1940. 


\section{References}

[1] Soong TT and Dargush GF. Passive energy dissipation systems in structural engineering. John Wiley \& Sons, Chichester, 1997.

[2] Hanson RD and Soong TT. Seismic design with supplemental energy dissipation devices. EERI, Oakland, CA, 2001.

[3] de Silva CW (ed.). Vibration damping, control, and design. CRC Press, 2007.

[4] Takewaki I. Building control with passive dampers: -Optimal performance-based design for earthquakes-. John Wiley \& Sons Ltd. (Asia), 2009.

[5] Takewaki I, Murakami S, Fujita K, Yoshitomi S and Tsuji M. The 2011 off the Pacific coast of Tohoku earthquake and response of high-rise buildings under long-period ground motions. Soil Dynamics and Earthquake Engineering 2011; 31(11): 1511-1528.

[6] Zhang RH and Soong TT. Seismic design of viscoelastic dampers for structural applications. J Struct Engrg, ASCE 1992; 118: 1375-1392.

[7] Tsuji M and Nakamura T. Optimum viscous dampers for stiffness design of shear buildings. J Structural Design of Tall Buildings 1996; 5: 217-234.

[8] Takewaki I. Optimal damper placement for minimum transfer functions. Earthq Engrg Struct Dyn 1997; 26: 1113-1124.

[9] Takewaki I. Optimal Damper placement for planar building frames using transfer functions, Structural and Multidisciplinary Optimization 2000; 20(4): 280-287.

[10] Garcia DL. A simple method for the design of optimal damper configurations in MDOF structures. Earthquake Spectra 2001; 17: 387-398.

[11] Singh MP and Moreschi LM. Optimal seismic response control with dampers. Earthq Engrg Struct Dyn 2001; 30: 553-572.

[12] Uetani K, Tsuji M and Takewaki I. Application of optimum design method to practical building frames with viscous dampers and hysteretic dampers. Engineering Structures 2003; 25: 579-592. 
[13] Liu W, Tong M and Lee G. Optimization methodology for damper configuration based on building performance indices. J Struct Engrg, ASCE 2005; 131(11): 1746-1756.

[14] Lavan O and Levy R. Optimal design of supplemental viscous dampers for linear framed structures. Earthq Engrg Struct Dyn 2006; 35: 337-356.

[15] Silvestri S and Trombetti T. Physical and numerical approaches for the optimal insertion of seismic viscous dampers in shear-type structures, J Earthquake Engineering 2007; 11: 787-828.

[16] Aydin E, Boduroglub MH and Guney D. Optimal damper distribution for seismic rehabilitation of planar building structures. Engineering Structures 2007; 29: 176-185.

[17] Cimellaro GP. Simultaneous stiffness-damping optimization of structures with respect to acceleration, displacement and base shear. Engineering Structures 2007; 29: 2853-2870.

[18] Attard TL. Controlling all interstory displacements in highly nonlinear steel buildings using optimal viscous damping. J Struct Engrg, ASCE 2007; 133(9): 1331-1340.

[19] Lavan O and Levy R. Optimal design of supplemental viscous dampers for irregular shear-frames in the presence of yielding. Earthq Engrg Struct Dyn 2005; 34(8): 889-907.

[20] Guyan RJ. Reduction of stiffness and mass matrices. AIAA J 1965; 3: 380.

[21] Tsuji M, Tanaka H, Yishitomi S and Takewaki I. Model reduction method for buildings with viscous dampers under earthquake loading. J Struct Construction Eng, Architectural Institute of Japan 2011; 76(665): 1281-1290 (in Japanese).

[22] Takewaki I and Yoshitomi S. Effects of support stiffnesses on optimal damper placement for a planar building frame. J. of The Structural Design of Tall Buildings 1998; 7(4): 323-336. 


\section{Captions of figures and tables}

Fig.1 (a) Planar building model, (b) Damping force-velocity relation of oil damper

Fig.2 Planar frame model and its reduced model

Fig.3 Effect of ratio of supporting member stiffness to story stiffness on response of interstory drifts

Fig.4 Damping coefficient distributions of oil dampers in frame model and reduced model

Fig.5 Relief load distributions of oil dampers in frame model and reduced model

Fig.6 Maximum interstory-drift distributions in frame model and reduced model

Fig.7 Maximum acceleration distributions in frame model and reduced model

Fig.8 Distributions of maximum damping force ratios (maximum response damping force/ relief force) in frame model and reduced model

Fig.9 Approximate solution procedure using reduced model

Fig.10 Relation of $D_{\max }, A_{\max }$ with $C_{d}$ in displacement design in case of damper allocation to all stories (final response is evaluated by frame model)

Fig.11 Relation of $D_{\max }, A_{\max }$ with $C_{d}$ in acceleration design in case of damper allocation to all stories (final response is evaluated by frame model)

Fig.12 Relief force distributions in displacement design for several levels in case of damper allocation to all stories

Fig.13 Relief force distributions in acceleration design for several levels in case of damper allocation to all stories

Fig.14 Maximum interstory-drift distributions in displacement design for several relief force levels in case of damper allocation to all stories (final response is evaluated by frame model)

Fig.15 Maximum interstory-drift distributions in acceleration design for several relief force levels in case of damper allocation to all stories (final response is evaluated by frame model)

Fig.16 Maximum acceleration distributions in displacement design for several relief force levels in case of damper allocation to all stories (final response is evaluated by frame model) 
Fig.17 Maximum acceleration distributions in acceleration design for several relief force levels in case of damper allocation to all stories (final response is evaluated by frame model)

Fig.18 Relation of $D_{\max }, A_{\max }$ with $C_{d}$ in displacement design in case of damper allocation to lower stories (final response is evaluated by frame model)

Fig.19 Relation of $D_{\max }, A_{\max }$ with $C_{d}$ in acceleration design in case of damper allocation to lower stories (final response is evaluated by frame model)

Fig.20 Relief force distributions in displacement design for several levels in case of damper allocation to lower stories

Fig.21 Relief force distributions in acceleration design for several levels in case of damper allocation to lower stories

Fig.22 Comparison of relation of $D_{\max }, A_{\max }$ with $C_{\mathrm{d}}$ in displacement design (Design D) between the optimal design with damper allocation to all stories and the optimal design with damper allocation to lower stories

Fig.23 Comparison of relation of $D_{\max }, A_{\max }$ with $C_{\mathrm{d}}$ in acceleration design (Design A) between the optimal design with damper allocation to all stories and the optimal design with damper allocation to lower stories

Fig.24 Maximum interstory drift and maximum top-floor acceleration for one hundred designs together with the response of the optimal design (Design D)

Fig.25 Maximum interstory drift and maximum top-floor acceleration for one hundred designs together with the response of the optimal design (Design A)

Fig.26 Displacement and acceleration response spectra (12\% damping) for three ground motions

Fig.27 Maximum damping force ratios (to relief force) for three ground motions in two damper allocations

Table 1 Member properties of frame

Table 2 Maximum interstory drifts and maximum top-story accelerations for three ground motions in two damper allocations (initial design) 
Table 1 Member properties of frame

\begin{tabular}{|c|c|c|c|}
\hline story & $I_{c}\left(\mathrm{~mm}^{4}\right)$ & $A_{c}\left(\mathrm{~mm}^{2}\right)$ & $I_{b}\left(\mathrm{~mm}^{4}\right)$ \\
\hline $1 \sim 5$ & 2162651392 & 46464 & 2920000000 \\
\hline $6 \sim 10$ & 1898898000 & 40356 & 1720000000 \\
\hline
\end{tabular}

Table 2 Maximum interstory drifts and maximum top-story accelerations for three ground motions in two damper allocations (initial design)

\begin{tabular}{|c|c|c|c|c|}
\hline & \multicolumn{2}{|c|}{ allocation to all stories } & \multicolumn{2}{c|}{ allocation to lower stories } \\
\hline Ground motion & $D_{\max }(\mathrm{mm})$ & $A_{\max }\left(\mathrm{mm} / \mathrm{s}^{2}\right)$ & $D_{\max }(\mathrm{mm})$ & $A_{\max }\left(\mathrm{mm} / \mathrm{s}^{2}\right)$ \\
\hline El Centro NS 1940 & 13.13 & 2859 & 15.90 & 3701 \\
\hline Taft EW 1952 & 8.020 & 1656 & 9.034 & 2270 \\
\hline Hachinohe NS 1968 & 11.27 & 2427 & 12.81 & 2831 \\
\hline
\end{tabular}

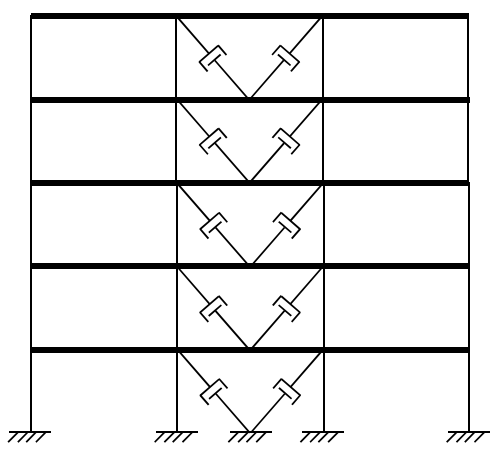

(a)

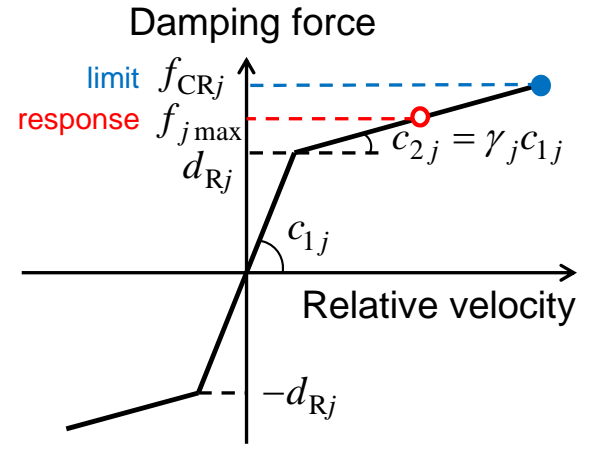

(b)

Fig.1 (a) Planar building model, (b) Damping force-velocity relation of oil damper

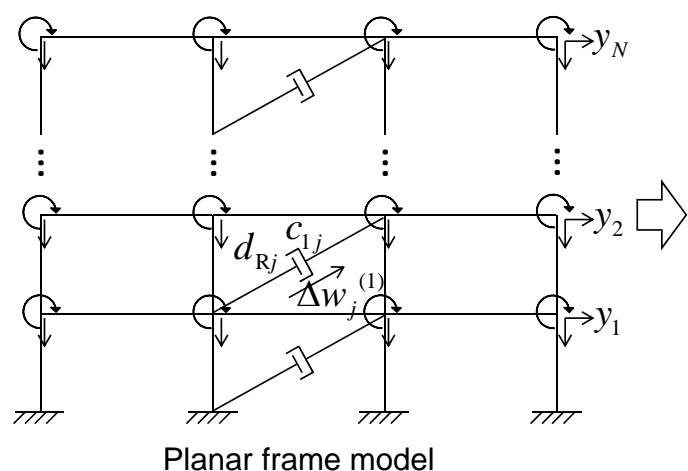

Fig.2 Planar frame model and its reduced model

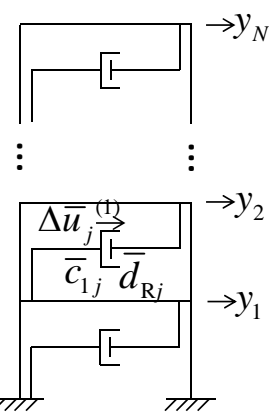

Reduced model 


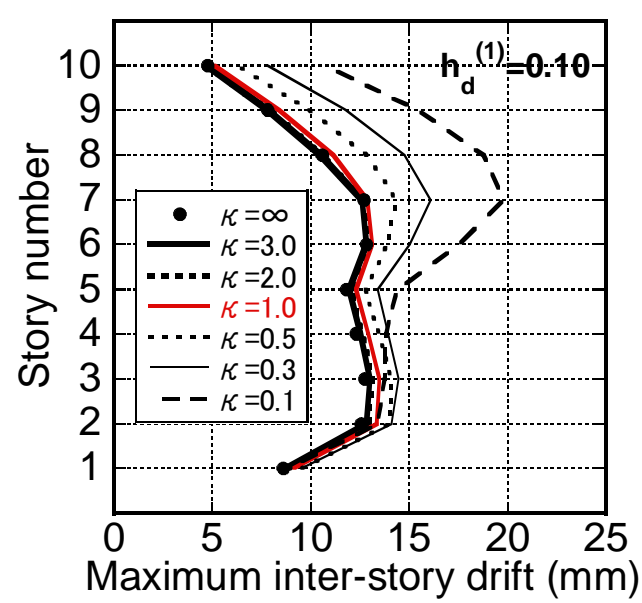

Fig.3 Effect of ratio of supporting member stiffness to story stiffness on response of interstory drifts

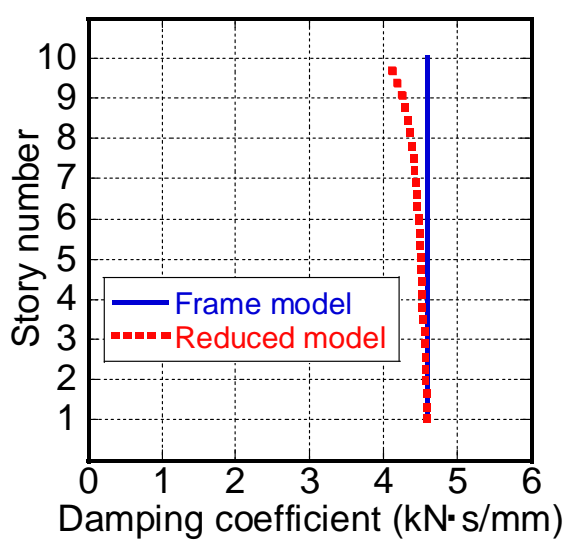

Fig.4 Damping coefficient distributions of oil dampers in frame model and reduced model

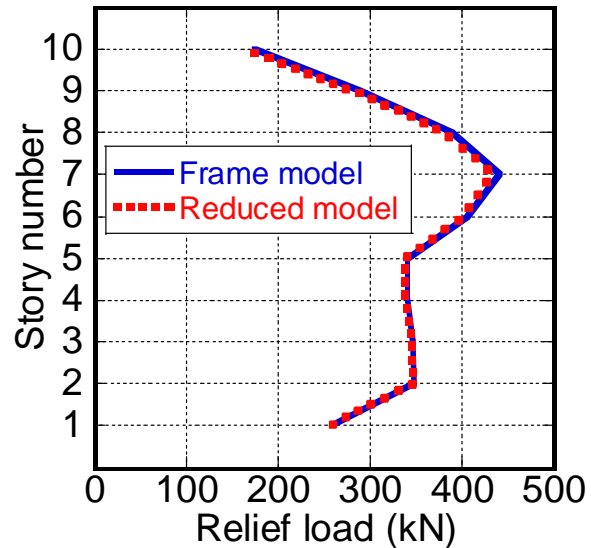

(a) $L=1.0$

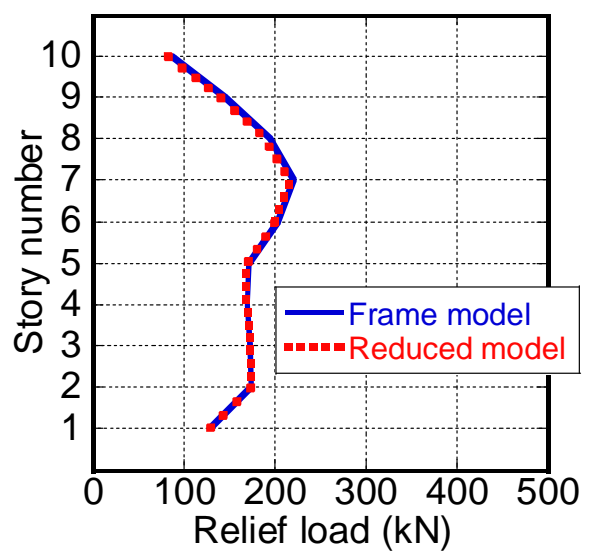

(b) $L=0.5$

Fig.5 Relief load distributions of oil dampers in frame model and reduced model 


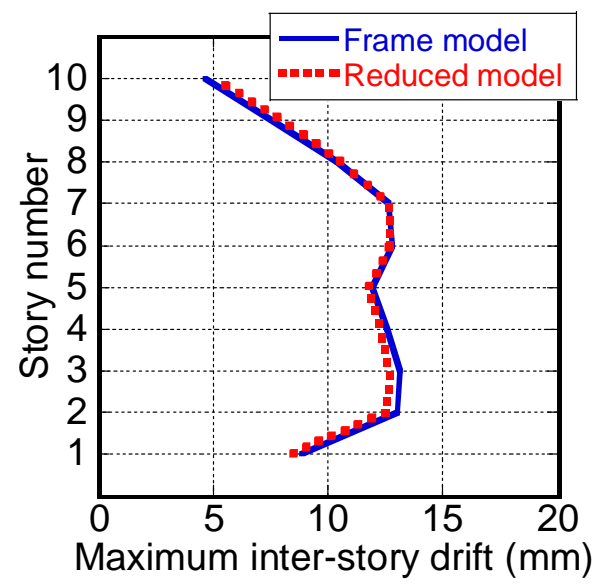

(a) $L=1.0$

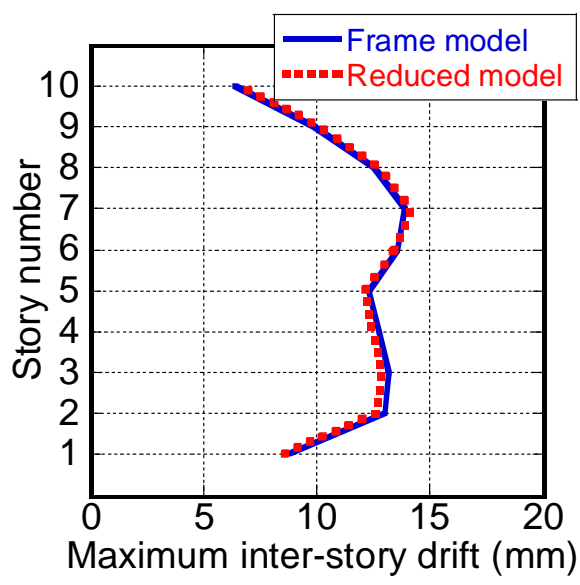

(b) $L=0.5$

Fig.6 Maximum interstory-drift distributions in frame model and reduced model

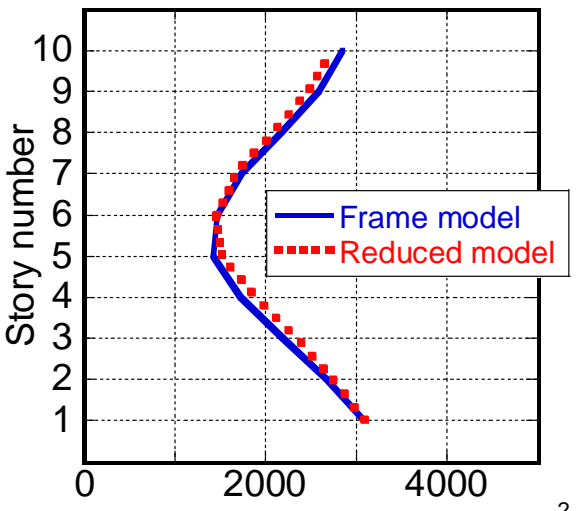

Maximum absolute acceleration $\left(\mathrm{mm} / \mathrm{s}^{2}\right)$

(a) $L=1.0$

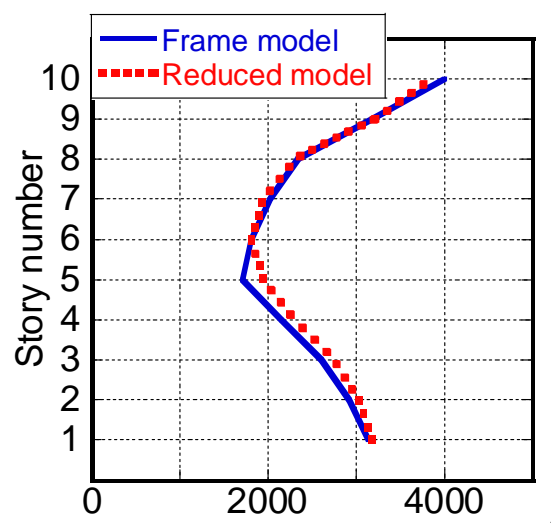

Maximum absolute acceleration $\left(\mathrm{mm} / \mathrm{s}^{2}\right)$

(b) $L=0.5$

Fig.7 Maximum acceleration distributions in frame model and reduced model

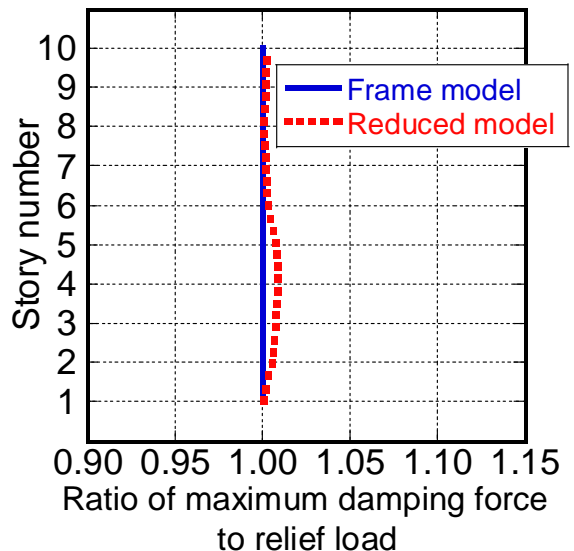

(a) $L=1.0$

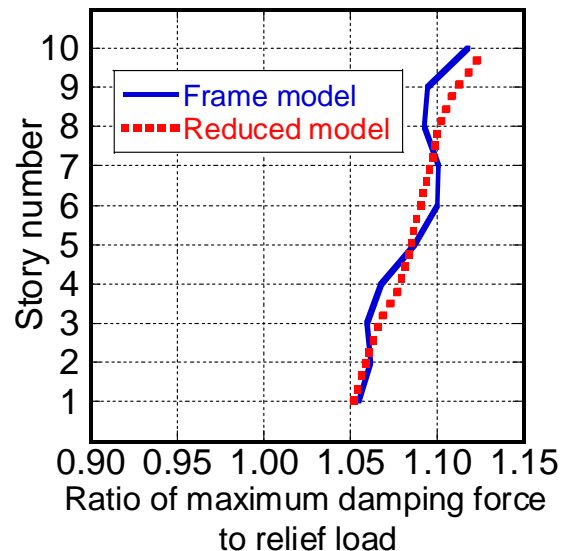

(b) $L=0.5$

Fig.8 Distributions of maximum damping force ratios (maximum response damping force/ relief force) in frame model and reduced model 


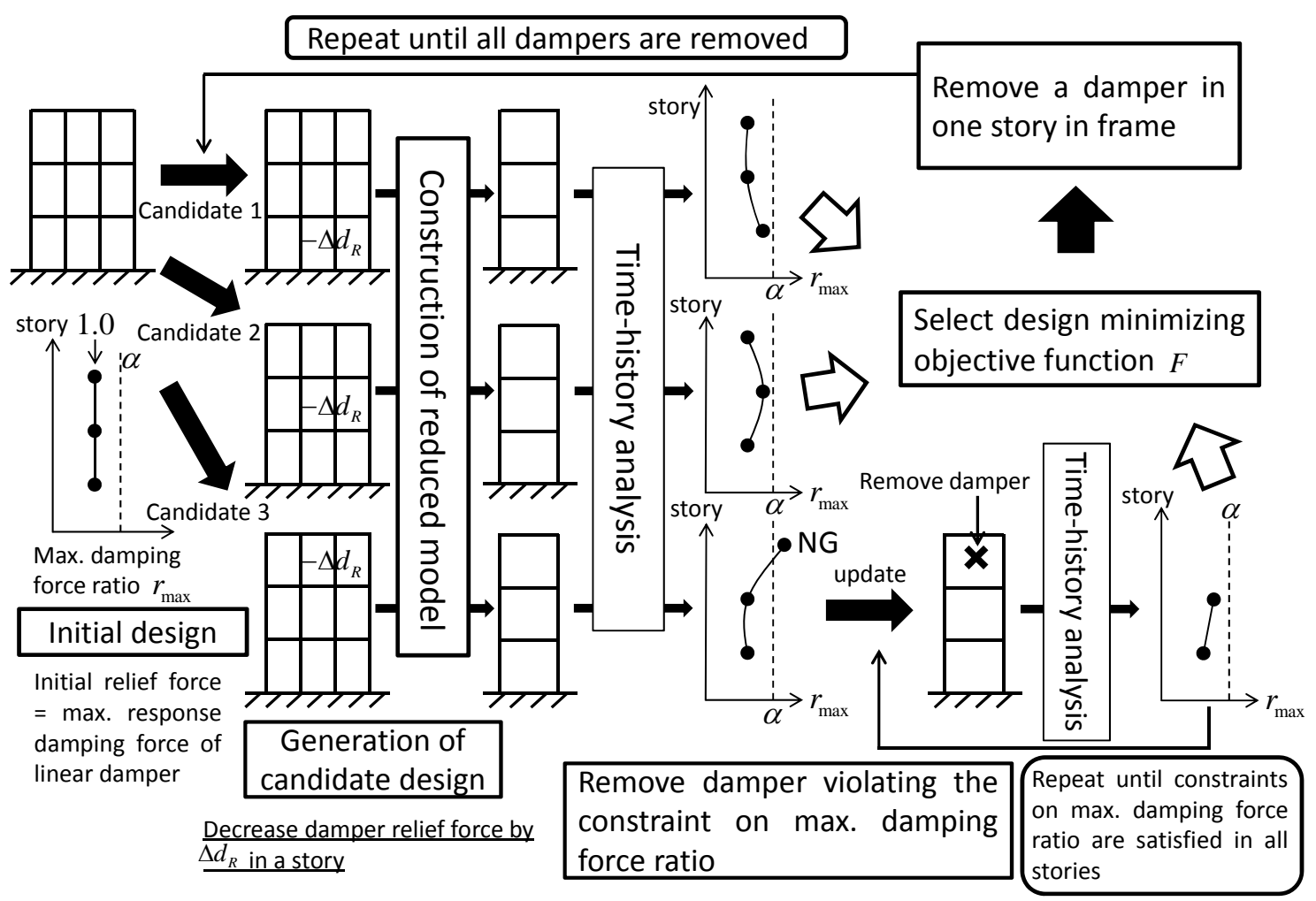

Fig.9 Approximate solution procedure using reduced model 


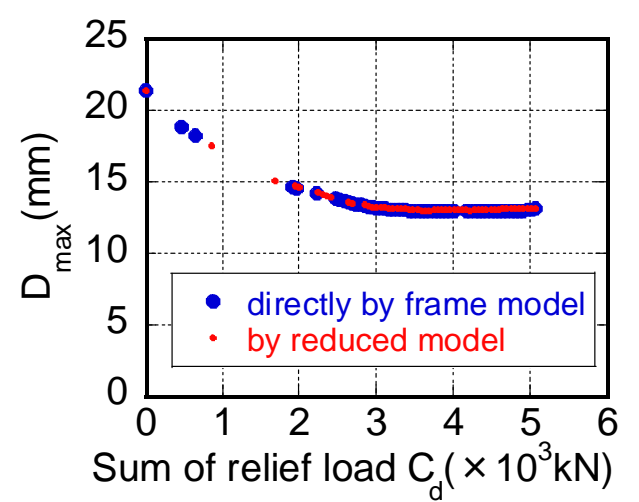

(a) $C_{\mathrm{d}}-D_{\max }$ relation

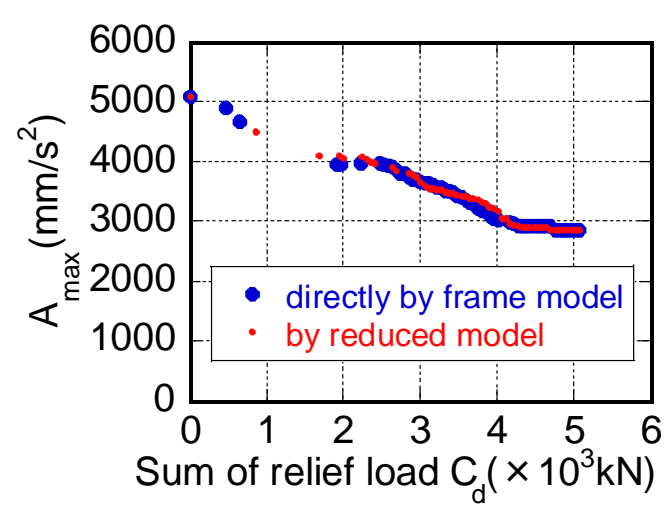

(b) $C_{\mathrm{d}}-A_{\max }$ relation

Fig.10 Relation of $D_{\max }, A_{\max }$ with $C_{\mathrm{d}}$ in displacement design in case of damper allocation to all stories (final response is evaluated by frame model)

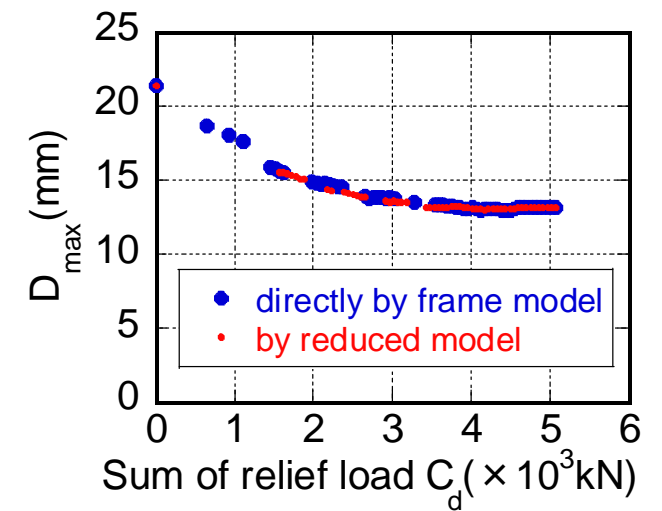

(a) $C_{\mathrm{d}}-D_{\max }$ relation

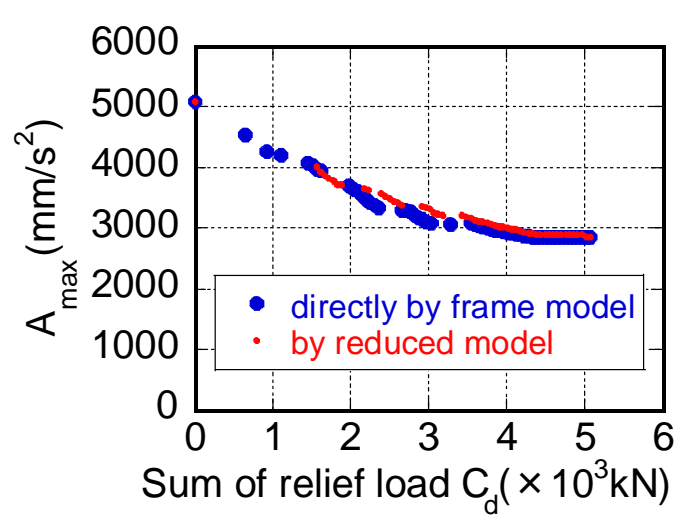

(b) $C_{\mathrm{d}}-A_{\max }$ relation

Fig.11 Relation of $D_{\max }, A_{\max }$ with $C_{\mathrm{d}}$ in acceleration design in case of damper allocation to all stories (final response is evaluated by frame model) 


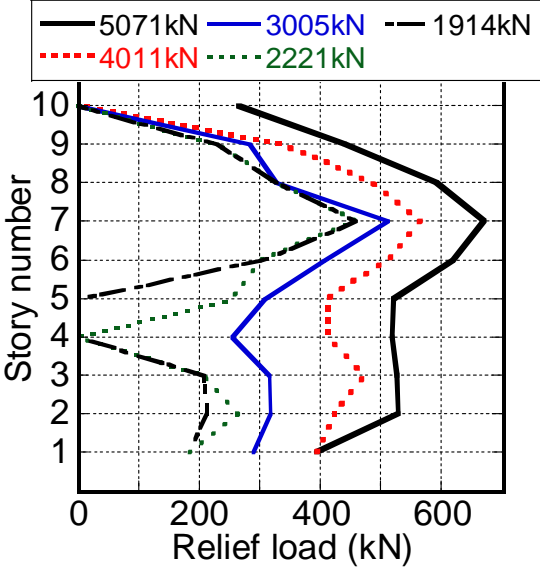

(a) optimization using frame model

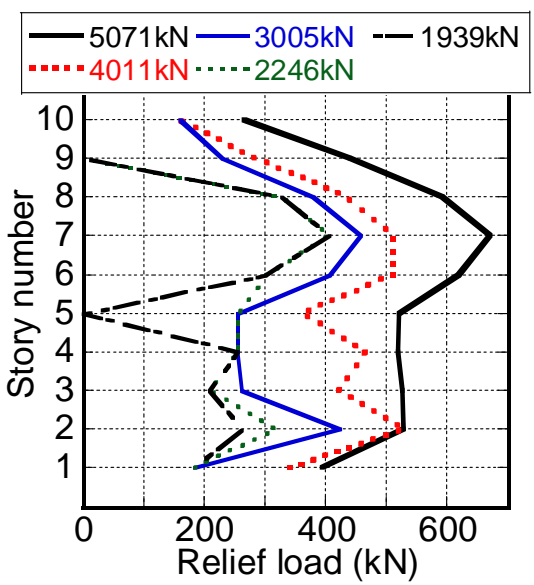

(b) optimization using reduced model

Fig.12 Relief force distributions in displacement design for several levels in case of damper allocation to all stories

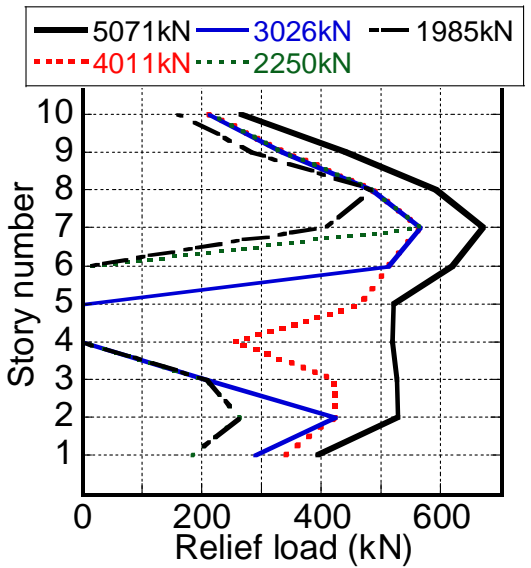

(a) optimization using frame model

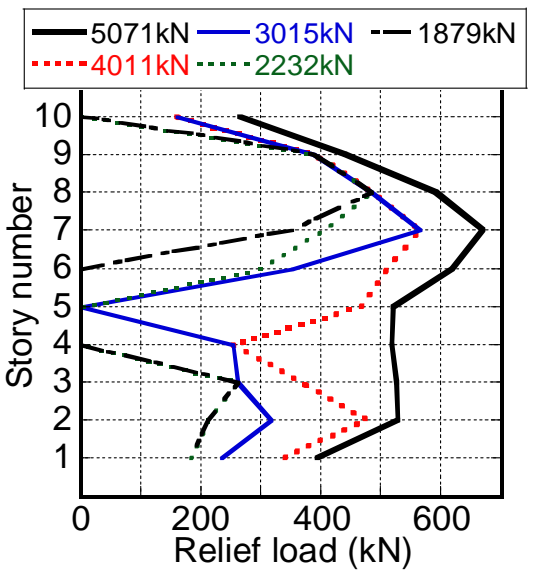

(b) optimization using reduced model

Fig.13 Relief force distributions in acceleration design for several levels in case of damper allocation to all stories 


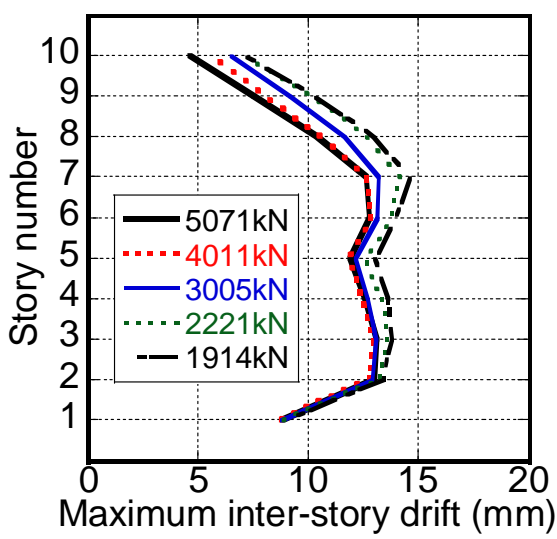

(a) optimization using frame model

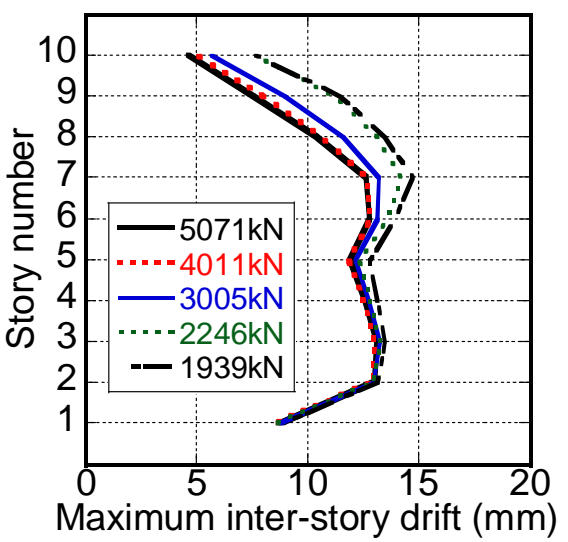

(b) optimization using reduced model

Fig.14 Maximum interstory-drift distributions in displacement design for several relief force levels in case of damper allocation to all stories (final response is evaluated by frame model)

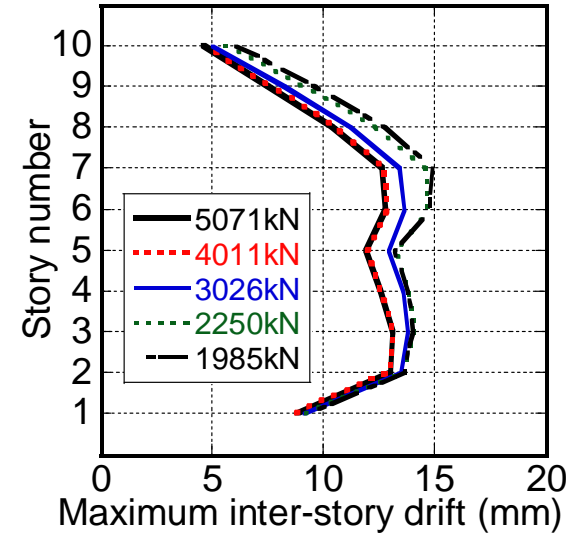

(a) optimization using frame model

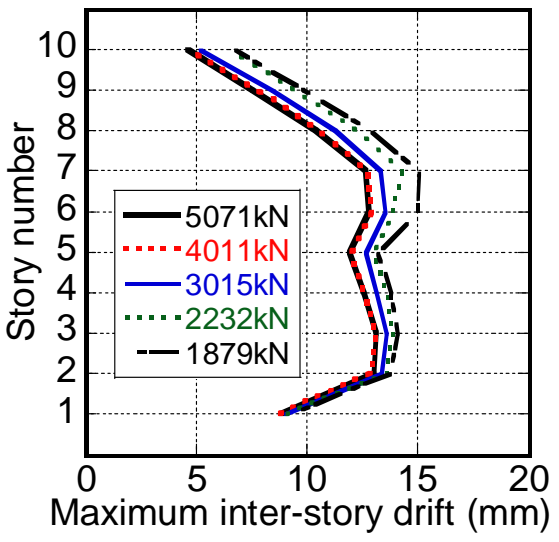

(b) optimization using reduced model

Fig.15 Maximum interstory-drift distributions in acceleration design for several relief force levels in case of damper allocation to all stories (final response is evaluated by frame model) 


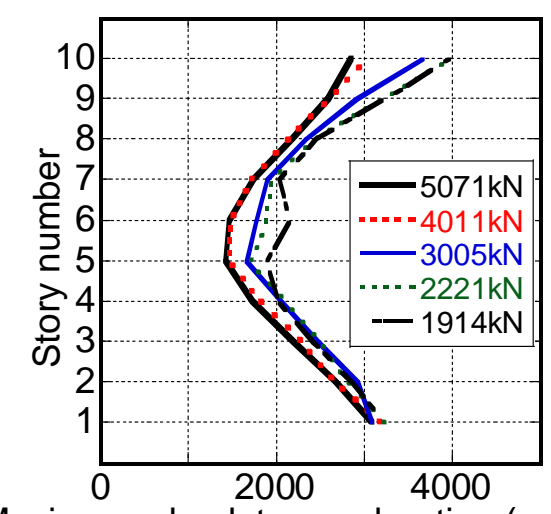

Maximum absolute acceleration $\left(\mathrm{mm} / \mathrm{s}^{2}\right)$

(a) optimization using frame model

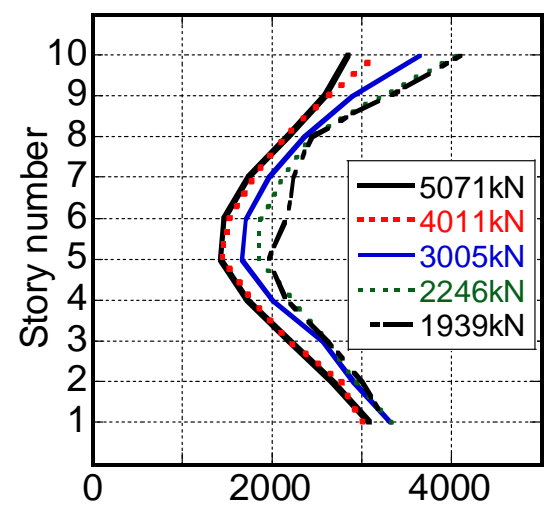

Maximum absolute acceleration $\left(\mathrm{mm} / \mathrm{s}^{2}\right)$

(b) optimization using reduced model

Fig.16 Maximum acceleration distributions in displacement design for several relief force levels in case of damper allocation to all stories (final response is evaluated by frame model)

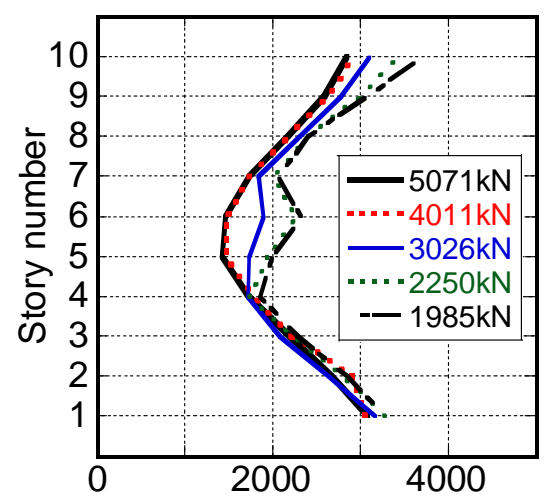

Maximum absolute acceleration $\left(\mathrm{mm} / \mathrm{s}^{2}\right)$

(a) optimization using frame model

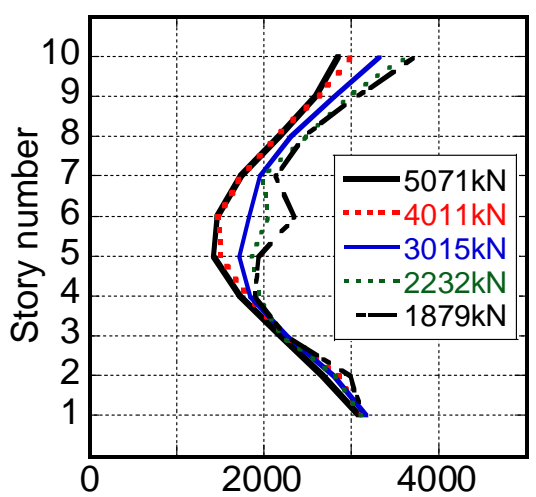

Maximum absolute acceleration $\left(\mathrm{mm} / \mathrm{s}^{2}\right)$

(b) optimization using reduced model

Fig.17 Maximum acceleration distributions in acceleration design for several relief force levels in case of damper allocation to all stories (final response is evaluated by frame model) 


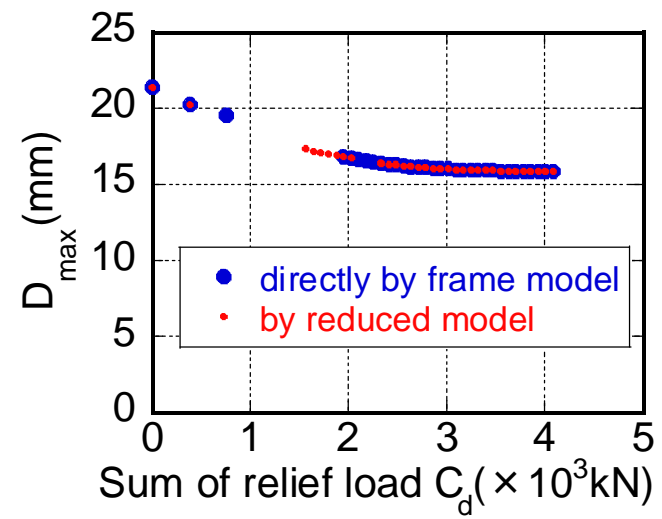

(a) $C_{\mathrm{d}}-D_{\max }$ relation

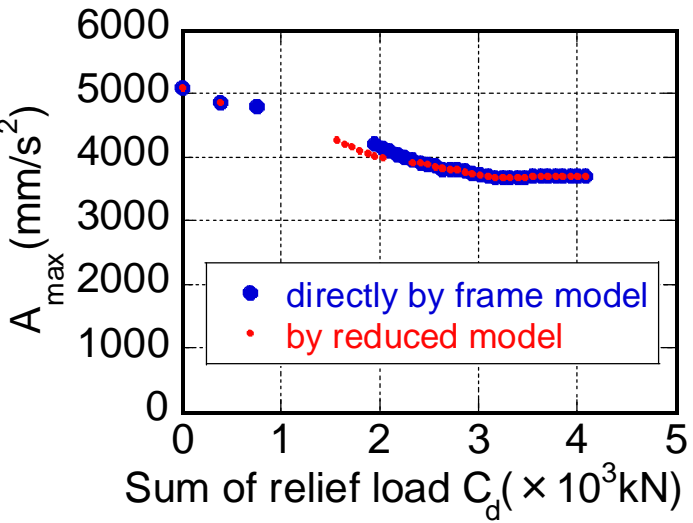

(b) $C_{\mathrm{d}}-A_{\max }$ relation

Fig.18 Relation of $D_{\max }, A_{\max }$ with $C_{\mathrm{d}}$ in displacement design in case of damper allocation to lower stories (final response is evaluated by frame model)

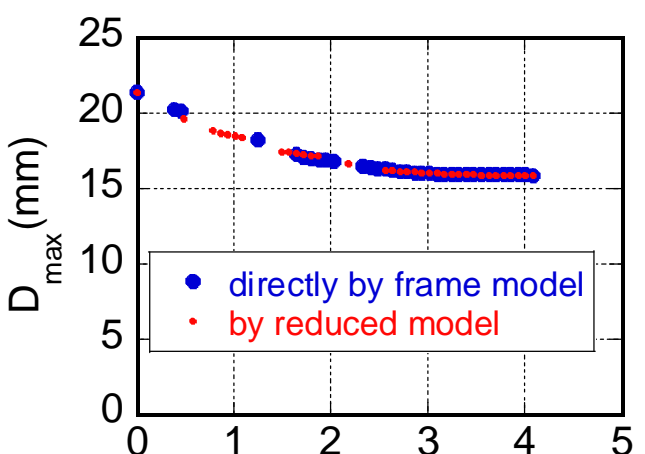

Sum of relief load $\mathrm{C}_{\mathrm{d}}\left(\times 10^{3} \mathrm{kN}\right)$

(a) $C_{\mathrm{d}}-D_{\max }$ relation

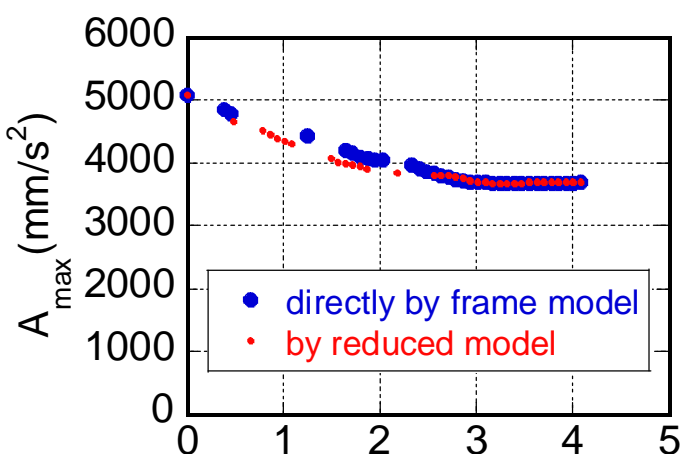

Sum of relief load $\mathrm{C}_{d}\left(\times 10^{3} \mathrm{kN}\right)$

(b) $C_{\mathrm{d}}-A_{\max }$ relation

Fig.19 Relation of $D_{\max }, A_{\max }$ with $C_{\mathrm{d}}$ in acceleration design in case of damper allocation to lower stories (final response is evaluated by frame model) 


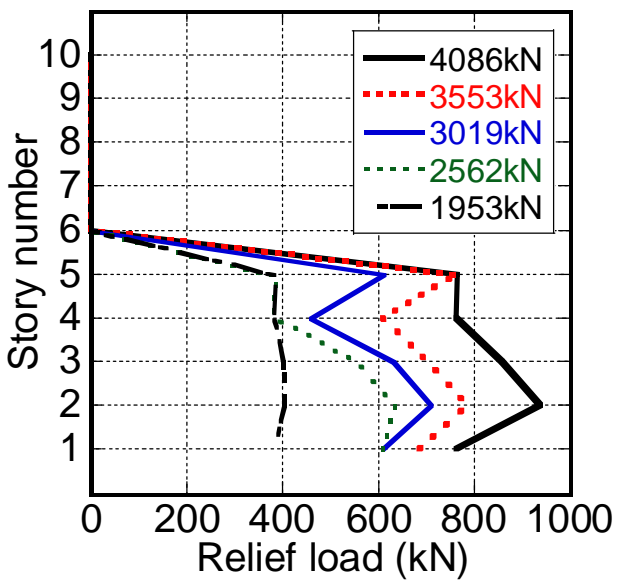

(a) optimization using frame model

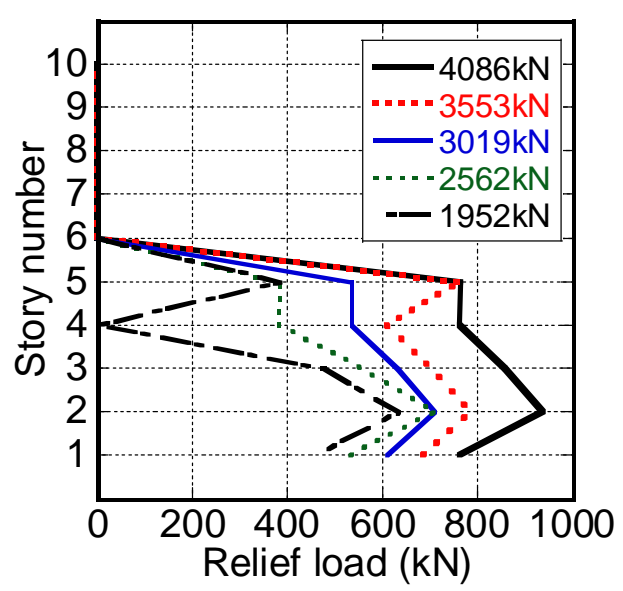

(b) optimization using reduced model

Fig.20 Relief force distributions in displacement design for several levels in case of damper allocation to lower stories

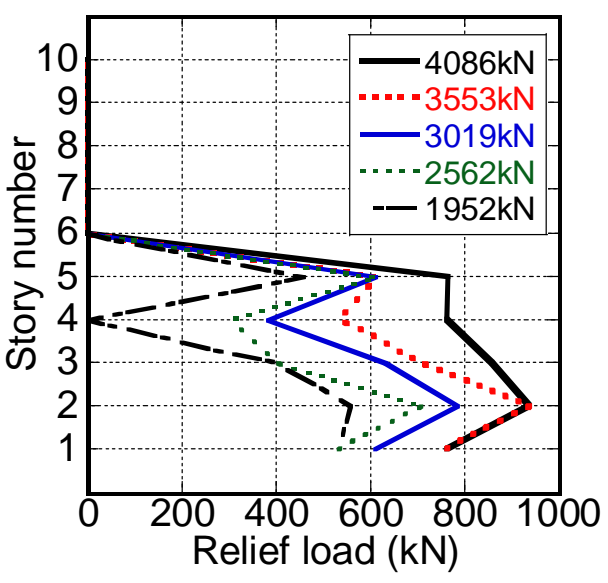

(a) optimization using frame model

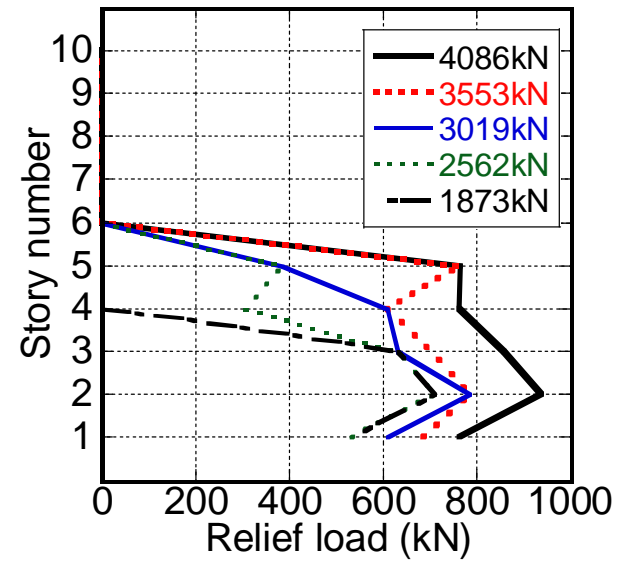

(b) optimization using reduced model

Fig.21 Relief force distributions in acceleration design for several levels in case of damper allocation to lower stories 


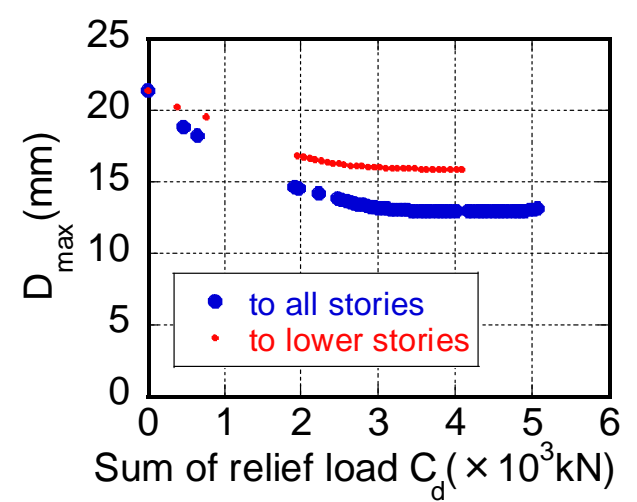

(a) $C_{\mathrm{d}}-D_{\max }$ relation

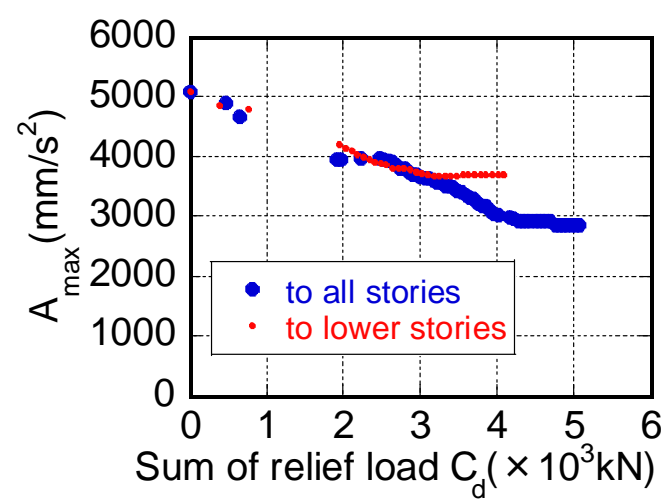

(b) $C_{\mathrm{d}}-A_{\max }$ relation

Fig.22 Comparison of relation of $D_{\max }, A_{\max }$ with $C_{\mathrm{d}}$ in displacement design (Design D) between the optimal design with damper allocation to all stories and the optimal design with damper allocation to lower stories

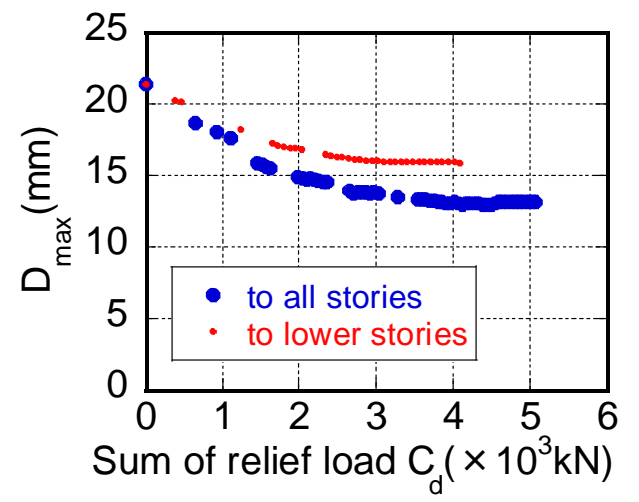

(a) $C_{\mathrm{d}}-D_{\max }$ relation

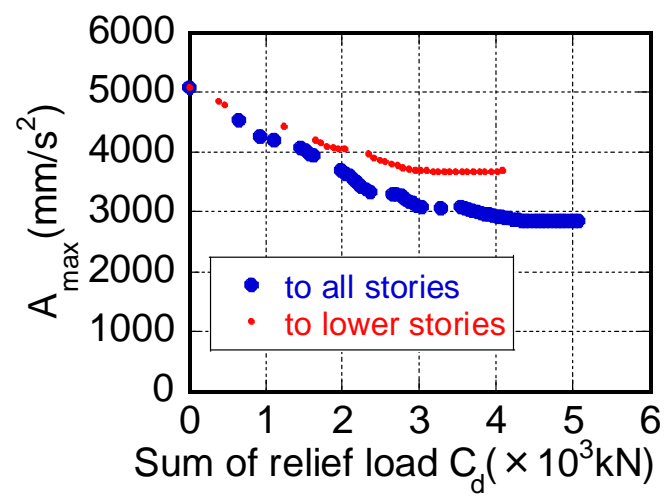

(b) $C_{\mathrm{d}}-A_{\max }$ relation

Fig.23 Comparison of relation of $D_{\max }, A_{\max }$ with $C_{\mathrm{d}}$ in acceleration design (Design A) between the optimal design with damper allocation to all stories and the optimal design with damper allocation to lower stories 

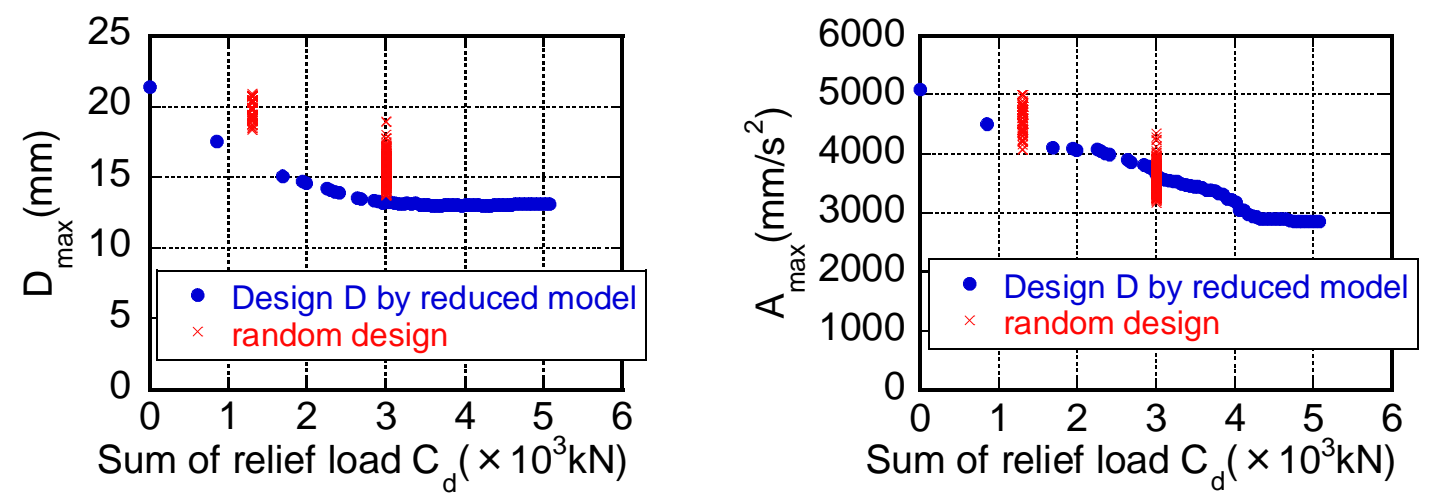

Fig.24 Maximum interstory drift and maximum top-floor acceleration for one hundred designs together with the response of the optimal design (Design D)
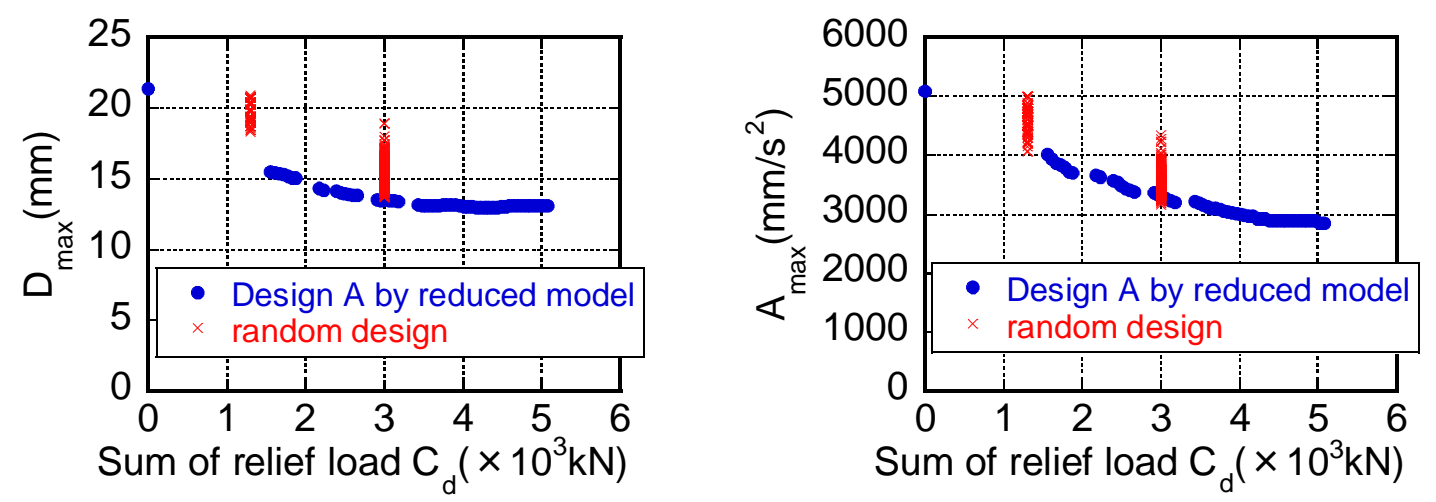

Fig.25 Maximum interstory drift and maximum top-floor acceleration for one hundred designs together with the response of the optimal design (Design A) 

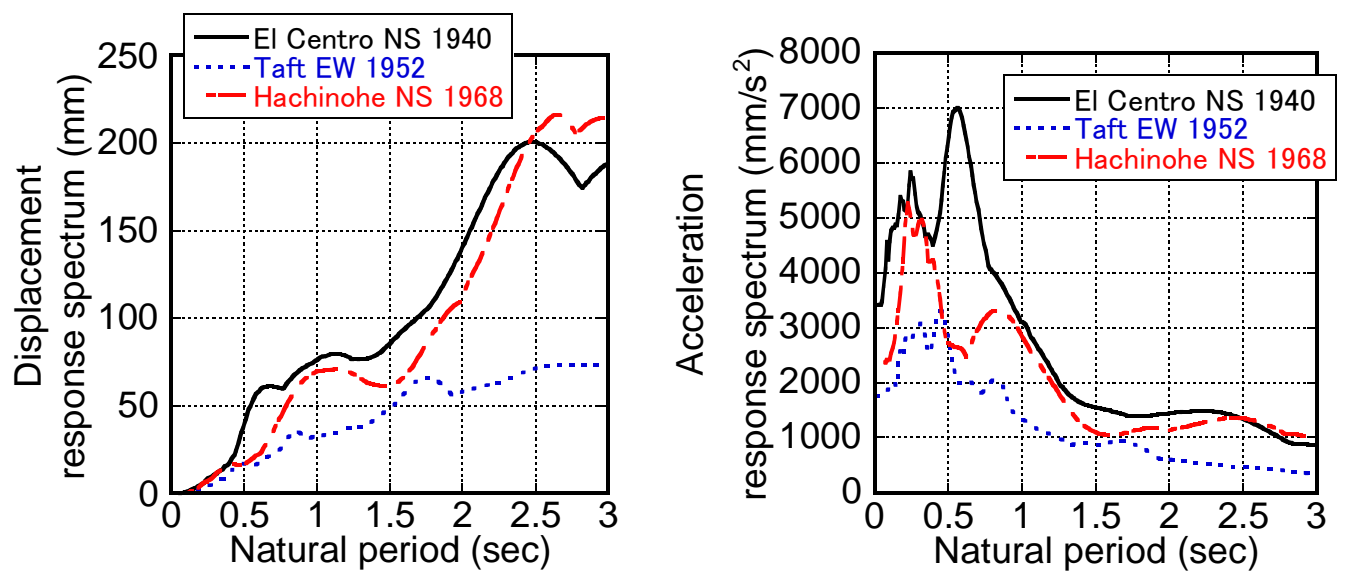

Fig.26 Displacement and acceleration response spectra (12\% damping) for three ground motions

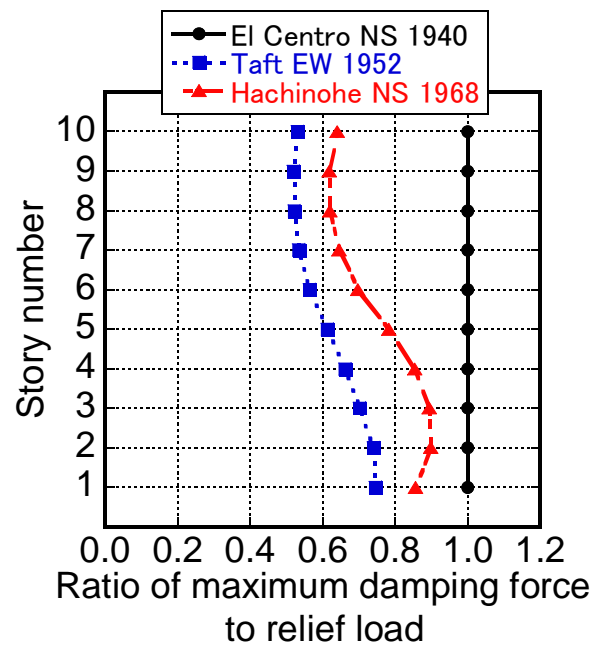

(a) allocation to all stories

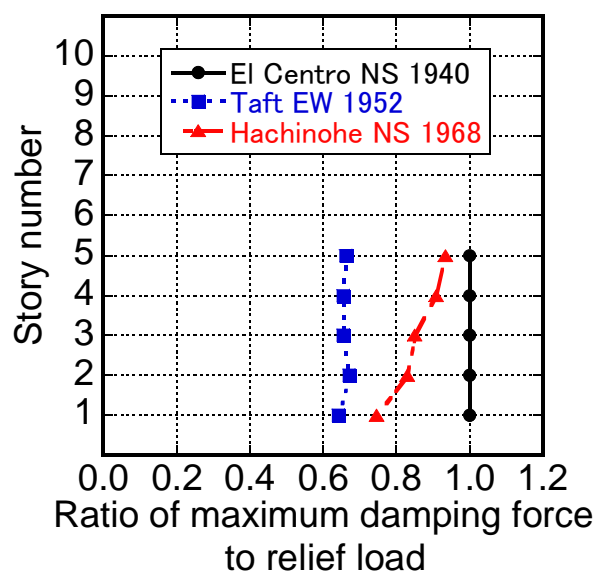

(b) allocation to lower stories

Fig.27 Maximum damping force ratios (to relief force) for three ground motions in two damper allocations 